\title{
Maize Drought and Flood Disaster Hazard Identification and its Response to Climate Change in Jilin,China
}

\author{
Danjun Li, Jiquan Zhang*, Enliang Guo, Rui Wang \\ School of Environment, Northeast Normal University, Institute of Natural Disaster Research, Northeast \\ Normal University, Changchun 130024, China

\section{吉林省玉米旱港危险性识别及其对气候变化的 响应} \\ 李丹君, 张继权"，郭恩亮，王聴 \\ 东北师范大学环境学院, 东北师范大学自然灾害研究所, 长春 130024 , 中国
}

\begin{abstract}
Jilin province is an important corn Production base in China. Due to climate change caused by meteorological disasters has a great influence on maize yield. The drought and rain waterlogging are common meteorological disasters during maize growth period. Using the temperature and precipitation data during maize growth period of Jilin province, we analyzed the trend of climate change. Further more, using the SPI index to identify the occurrence of drought and rain waterlogging, and by using probability density curve of SPI, we can characterize the risk of drought and rain waterlogging during maize growth period in Jilin. Further combining with the maize production data in Jilin province, we can get the analysis of the impact of climate change on maize yield.

Keywords: Climate change; drought; rain waterlogging, SPI

摘要
吉林省是我国重要玉米生产基地。由于气候变
化导致的气象灾害对玉米产量有很大影响。其
\end{abstract}

*通讯作者: 张继权, Zhangjq022@nenu.edu.cn
中干早和雨涝是玉米生育期常见的气象灾害。 利用吉林省玉米生育期的气温和降水数据分 析了气候变化趋势。利用 SPI 指数识别干旱和 雨涝的发生情况, 并利用 SPI 的概率密度曲线 表征吉林省玉米生育期干旱和雨涝的危险性。 进一步结合吉林省玉米生产数据分析气候变 化对玉米产量的影响, 可以得出: 气候变暖导 致吉林省玉米生育期温度上升, 降水量减少, 使得干旱灾害发生频率高于雨涝灾害; 由于气 候变化导致的极端天气事件频发, 致使减产的 发生, 需要对农业气象灾害进行更多的研究。

关键词: 气候变化; 干旱; 雨涝; SPI

1. 引言

吉林省位于 $121^{\circ} 38^{\prime}-131^{\circ} 17^{\prime} \mathrm{E}, 40^{\circ} 51^{\prime}$ - $46^{\circ} 18^{\prime} \mathrm{N}$ 之间, 是我国东北地区的中心地 带。 ${ }^{[11}$ 属于温带季风气候并且大陆性明显。吉 林省是我国的东北玉米带中重要的一部分, 同 时也是我国东北玉米主产区。在玉米生长发育 过程中, 干旱和洪涝灾害的发生将会导致减产, 不利于玉米种植。近百年来, 全球性的气候变 化使得地球环境出现诸如海平面上升, 臭氧层 


\section{Risk Analysis and Crisis Response in Big Data Era (RAC-16)}

空洞以及极端天气频发等现象。由于化石燃料 燃烧以及乱砍滥伐导致的地球环境恶化, 沙漠 化加剧、冰川融化以及河道断流, ${ }^{\left[{ }^{41}\right.}$ 这种全球 变暖背景下与气候条件密不可分的农业种植 将面临着重大挑战。因此研究在气候变化背景 下的玉米旱涝灾害显得尤为必要。本文选取吉 林省作为研究区, 利用近 50 年降水量和月平 均气温数据和产量数据, 分析了气候变化背景 下的减产情况, 得出较好的结论。

\section{2. 数据处理及研究方法}

\section{1 数据来源}

选取了吉林省 28 个气象观测站点的 1961 年到 2010 年逐日气象数据, 包括了最高气温、最 低气温、日均温、降水量、风速、相对湿度及 实际水汽压数据。生产资料则包括 19612010 年吉林省各区产量数据。

\section{2 研究方法}

气象资料处理: 将 28 个气象站点的 19612010 年气温和降水量的逐日数据, 利用 Fortran 语言处理成各个站点每月的平均气温、 最高和最低气温的平均值; 将玉米生育期内 (5 到 9 月份) 降水量进行累计, 然后平均得到吉 林省地区的平均值。

SPI 指数: 标准化降水指标, 能够较好的展现 干旱和涝发生的强度以及持续的时间。 ${ }^{\mathbf{I} 1}$ 该指 标是通过计算降水量在测评时间段内的分布 概率, 标准化处理后得到标准化降水的累计频 率分布情况进行干旱和洪涝的等级划分。 ${ }^{151}$ 能 够表现降水情况对作物生长的影响。本文中的 SPI 等级划分标准采用 GB/T20481-2006 气象 干旱等级标准并综合干旱等级标准增加雨涝 划分 ${ }^{61}$ 标准见表 1 。为了保持数据的完整性, 这里我们选用 28 个气象站点中有完整数据的 21 个气象站点做 SPI 指数计算。

表 1. SPI 等级划分表

\begin{tabular}{cc}
\hline SPI & 等级 \\
\hline $\mathrm{SPI} \geq 2.0$ & 极涝 \\
$1.5 \leq \mathrm{SPI}<2.0$ & 重涝 \\
$1.0 \leq \mathrm{SPI}<1.5$ & 中涝 \\
$0.5 \leq \mathrm{SPI}<1.0$ & 轻涝 \\
$-0.5<\mathrm{SPI}<0.5$ & 接近正常 \\
$-1.0<\mathrm{SPI} \leq-0.5$ & 轻旱 \\
$-1.5<\mathrm{SPI} \leq-1.0$ & 中旱 \\
$-2.0<\mathrm{SPI} \leq-1.5$ & 重早 \\
$\mathrm{SPI} \leq-2.0$ & 极早 \\
\hline
\end{tabular}

\section{3 减产率}

农业实际的产量由趋势产量 $\left(Y_{t}\right)$ 及气象产量 $\left(Y_{w}\right)$ 共同影响, 相对气象产量 $Y_{\mathrm{r}}$ 表示产量波 动, 是偏离趋势产量的程度, 其中

$$
\mathrm{Yr}=\frac{\mathrm{Yw}}{\mathrm{Yt}} \times 100 \%
$$

当 $Y_{r}<0$ 时表示气候导致作物发生减产。【21

\section{4 危险性评价指标}

干旱和涝灾的识别指标有很多, 其中干旱又可 以分为气象干旱、水文干旱、农业干旱以及社 会经济干旱。 ${ }^{\mathbf{l} 31}$ 涝则可以通过遥感等技术手段
进行识别与监测。本文通过 SPI 指数来进行干 旱和雨涝的等级划分, 其危险性则利用得到的 SPI 概率分布曲线表征, 因此其危险性表示为:

$$
\begin{aligned}
& \text { 干旱: } D H_{i}=\int_{-0.5}^{-3.5} S P I \times f(\mathrm{SPI}) \\
& \text { 雨涝: } F H I_{i}=\int_{0.5}^{3.5} S P I \times f(\mathrm{SPI})
\end{aligned}
$$

其中, DHI 表示为干旱的危险性, FHI 表示为 雨涝危险性, i 表示年代 ( $i=60 、 70 、 80 、 90$ 、 21 世纪初) SPI 为干早等级, $f(S P I)$ 表示 SPI 发生频率。 
Risk Analysis and Crisis Response in Big Data Era (RAC-16)

\section{3. 结果分析}

\section{1 气候变化情况}

由图 1 可以看出, 1961 年到 2010 年间, 气候资源变化较为明显。总体来看, 5 到 9 月 的平均气温有着明显的上升趋势, 符合全球变 暖的大气候背景。其中，5 月和 9 月的平均气 温变化情况较为一致, 而 5 月气温在 1984 年 附近有个明显的峰值, 基本趋势是 5 月平均气 温增长 $0.334^{\circ} \mathrm{C} / 10 \mathrm{a}$ 。 7 月和 8 月的增长较为 平缓, 9 月份的平均气温变化较为明显, 而进
入 21 世纪后, 平均气温有明显的上升趋势。

降水量的年际变化波动较大。1961 年到 2010 年的多年平均年总降水量为 $525 \mathrm{~mm}$, 峰值在 1987 年附近, 在 2009 年为最低值。6 0 年代到 21 世纪初期的年降水量的年代之和分别为 $5386.652 \mathrm{~mm} 、 5091.508 \mathrm{~mm}$ 、5594. $112 \mathrm{~mm}$ 、 $5291.9 \mathrm{~mm}$ 和 $4890.728 \mathrm{~mm}$, 总量出现了下降趋 势。

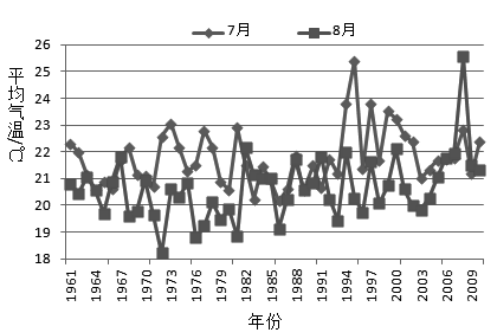

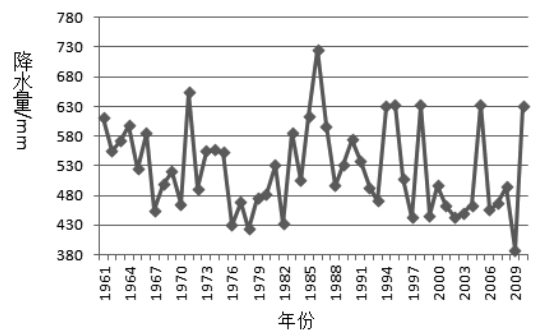

图 1. 1961 年到 2010 年吉林省玉米生育期内气候资源变化情况

\section{2 危险性及其与气候变化关系}

SPI 指数可以计算 $1 、 3 、 6$ 和 12 个月的 时间尺度, 由于吉林省的玉米生育期是 5-9 月份, 为了覆盖玉米全生育期, 我们利用 9 月 份的 SPI一6 来表征降水对玉米生长的影响状 况 ${ }^{171}$ 。进一步计算得出每个年代的 SPI 概率密 度曲线, 得到不同年代的各个气象站点的危险 性。

借助 SPI 的概率密度分布情况我们可以 得到不同年代吉林省的玉全生育期的旱涝危 险性, 见图 2。可以明显看出, 60 年代到 80 年代间, 概率密度曲线偏向右侧, 表面该三个 年代玉米生育期的雨涝发生频率要高于干旱,
而在 90 年代和 21 世纪初期, 明显出现了曲线 左偏现象, 表面干旱发生频率高于雨涝。分析 旱涝的危险性和气候变化情况可以发现, 随着 吉林省平均气温逐渐升高, 降水量减少的趋势, 全省的干旱危险性已经高于雨涝的危险性, 且 概率密度曲线左偏趋势年代间变化明显, 需要 注意玉米生育期的防旱。

\section{3 玉米产量变化}

图 3 为吉林省全省玉米平均产量以及其 减产年际变化。依据图 $3 \mathrm{a}$ 可以看出, 总体分 析吉林省玉米平均产量是呈现出逐年上升的 趋势, 每年平均亩产增量约为 8.88 公斤。 20 
Risk Analysis and Crisis Response in Big Data Era (RAC-16)

世纪 80 年代以来, 平均产量的年际波动较大, 一方面是由于种植和吉林省政策变动, 另一方 面则是由于气候变化影响。图 $3 \mathrm{~b}$ 可以看出减
产率的波动情况较为明显, 年际差异较大。其 中很大一部分的原因是由于气候变化导致的 气候产量波动, 由于极端天气事件发生, 导致
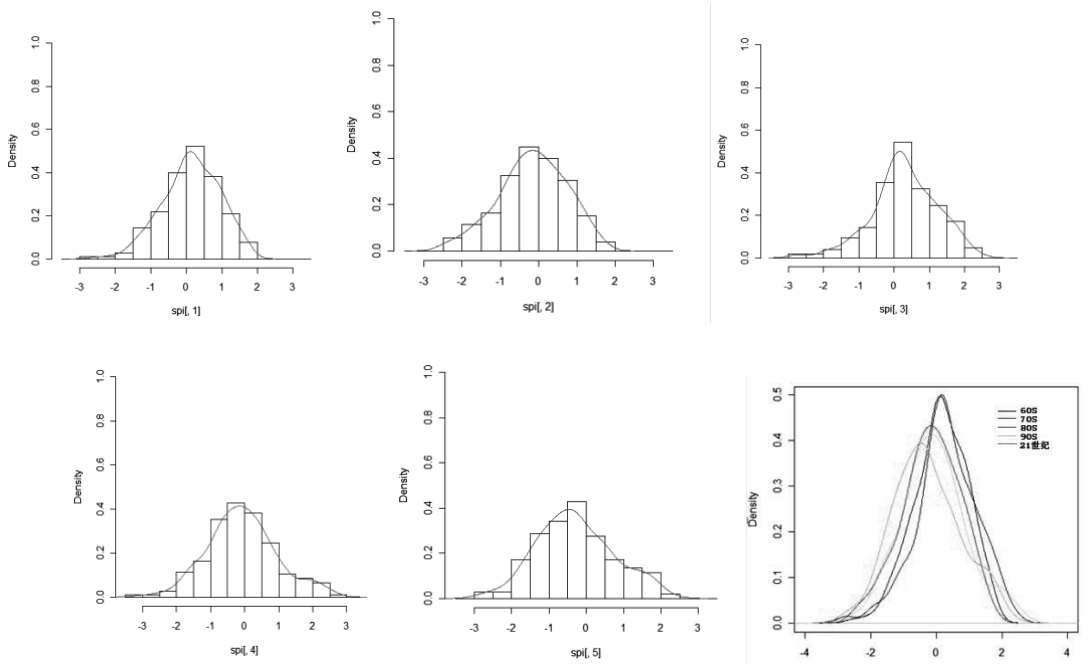

图 2. 吉林省玉米生育期不同年代 (20 世纪: SPI1_60 年代、SPI2_70 年代、SPI3_80 年代、SPI4_90 年代、 SPI5_21 世纪）SPI 概率密度分布图
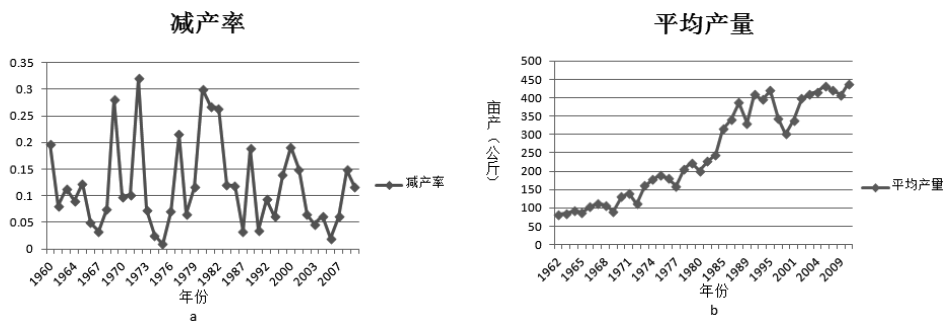

图 3. 吉林省玉米减产率 (a) 及平均产量 (b)

玉米减产率有显著的年际变化。

80 年代以来, 吉林省为玉米种植投入大 量研究, 培育了能够抵抗中旱和中度雨涝灾害 的玉米品种, 另外发展了地膜技术, 肥料生产 也更加适合地区发展, 因此玉米产量逐年升高, 减产率相较于 60 和 70 年代也出现下降趋势。

\section{4. 结论与讨论}

本文选取吉林省作为研究区, 利用 1961 年到 2010 年的降水量和月平均气温数据研究全省 气候变化情况, 进一步利用标准化降水指数的 概率密度曲线来表征全省的不同年代间的旱
涝危险性。结合吉林省产量数据分析了气候变 化背景下的减产情况, 得出的结论如下:

（1）吉林省 1961 年以来近 50 年间, 玉米生 育期的平均气温有着明显上升趋势, 降水量呈 现出下降趋势。其中 5 月和 6 月、9 月平均气 温的增长趋势明显, 7 月和 8 月增温现象则较 为平缓, 符合当下全球气候变暖趋势 ${ }^{\mathbf{8} 1}$ 。降水 量自 20 世纪 80 年代以来波动明显, 2009 年 达到了近 50 年来的最低值。

（2）由于全省的气候变化情况是气温升高降 水减少, 导致了 SPI 的概率密度曲线由 60 和 70 年代的偏右变为偏左, 说明吉林省的干旱 
Risk Analysis and Crisis Response in Big Data Era (RAC-16)

危险性显著上升, 需要在玉米生育期注意灌溉 并选种有抗旱特点的玉米品种, 以应对气候变 化对农业生产的影响。

(3) 由于 80 年代以来吉林省对农业发展的投 入, 使得玉米的平均产量逐步升高, 减产率相 较于 $60 、 70$ 年代有了明显的下降。但是由于 极端天气事件频发导致的气候产量波动不容 忽视, 需要在今后的研究中考虑气候波动带来 的影响, 使得吉林省减产率进一步的减小。

\section{Acknowledgements}

This study was supported by "Twelfth five-year" science and technology support project (2011BAD32B00-04) and National Natural Science Foundation (41571491) and the National Non-Profit Research Program of China (No.201401015)..

\section{致谢}

本研究得到了国家 “十二五” 科技支撑项目 (2011BAD32B04)、国家自然科学基金项目 (41571491) 和水利部公益性行业科研专项经 费项目（201401015）的支持。

\section{参考文献:}

[1] 张继权, 梁警丹, 周道玮. 基于 GIS 技术 的吉林省生态灾害风险评价。应用生态 学报, 2007, 18(8):1765-1770.

[2] 孟林, 王春乙，任义方,等. 长江中下游一 季稻高温热害危险性特征及其对气候变 化的响应. 自然灾害学报, 2015(6): 80-89.

[3] 赵丽, 冯宝平, 张书花. 国内外干旱及干 旱指标研究进展. 江苏农业科学, 2012, 40(8):345-348.

[4] 李柏贞, 周广胜. 干旱指标研究进展. 生 态学报, 2014, 34(5):1043-1052.

[5] 陈小风. 干早指标研究现状与展望. 治淮, 2016(2):16-17.

[6] 车少静, 李春强, 申双和. 基于 SPI 的近 41 年(1965-2005)河北省旱涝时空特征分 析. 中国农业气象, 2010, 31(1):137-143.

[7] 张琪, 朱萌, 张继权, 骆晓龙, 乌兰. 气候 变化背景下吉林干旱风险识别研究风险 分析和危机反应中的信息技术, 黄崇福, 包玉海, 赵思健编. 巴黎: Atlantis 出版社, pp. 486-489, 2014.

[8] H. Hao, P. Long, S. Curtis. Attitudes of property owners to climate change considerations and their effects on future property values in coastal communities. Journal of Risk Analysis and Crisis Response, 2012, 2(4):285-291. 